\title{
PROBLEMATIZANDO O PROCESSO ENSINO-APRENDIZAGEM EM ENFERMAGEM EM SAÚDE MENTAL
}

\author{
DISCUSSING THE EDUCATION-LEARNING PROCESS IN NURSING GRADUATION RELATED TO \\ MENTAL HEALTH
}

\author{
Sônia Barros 1 \\ Roselma Lucchese 2
}

Resumo $\mathrm{O}$ artigo apresenta um projeto de pesquisa que problematiza a formação de graduandos na área de saúde mental, especialmente os de enfermagem. Reconhecemos que é necessário aprofundar estudos junto às novas tendências pedagógicas, visando a romper com o modelo tradicional de educação que privilegia a transferência de conhecimento como um fim em si mesmo, a pouca flexibilidade dos currículos e a rigidez dos papéis do professor e do aluno, fatores que impedem a formação crítico-reflexiva dos profissionais. Diante desta problemática, fomos buscar na pedagogia das competências amparo teórico para a mudança necessária no sentido de melhorar e atualizar o processo ensino-aprendizagem. Propomos um diálogo entre a prática e o ensino da assistência de enfermagem psiquiátrica e de saúde mental, em que docentes e enfermeiros trabalhadores possam indicar um caminho para a identificação e construção das competências necessárias para que o enfermeiro atue eficazmente em situações reais na saúde mental ${ }^{3}$.

Palavras-chave pedagogia das competências; processo ensino-aprendizagem; saúde mental; enfermagem.
Abstract The article shows a research project which discusses the graduation program within mental health field, specially the nursing course. We admit that it is necessary to improve studies concerning to new pedagogical tendencies, aiming to overcome the traditional education model which privileges the knowledge transference as a purpose itself, the little flexibility of curriculums and the professors and students stiff performance, factors that prevent the critical-reflexive development of professionals. Before this problem, we searched on competencies pedagogy, a theoretical support for necessary changes in the sense to improve and update the education-learning process. We suggest a dialogue between practice and assistance education on psychiatric and mental health nursing, on which teachers and nurses may indicate a way to identify and build necessary capacities to enable nurses to act with efficacy in real situations present in mental health.

Key words competencies pedagogy; educationlearning process; mental health; nursing. 


\section{Introdução}

O exercício da docência leva a uma constante reflexão sobre o processo ensino-aprendizagem e à necessidade de formar profissionais críticos, ativos e reflexivos, agentes de transformação da realidade.

Estudos desenvolvidos em nossa linha de pesquisa "Políticas e práticas em saúde mental", no Programa de Pós-Graduação da Escola de Enfermagem da Universidade de São Paulo (USP), têm revelado que o ensino de enfermagem na área de saúde mental enfoca um saber-instrumento que não é posto em prática no processo assistencial pelo sujeito do trabalho - o enfermeiro (Barros e Egry, 2001).

Por outro lado, há consenso na literatura sobre o temor dos alunos ao cursarem a disciplina de enfermagem psiquiátrica e de saúde mental. Vaie (2002), ao realizar investigação com a finalidade de compreender a vivência deste aluno, concluiu que a disciplina pode ser caracterizada como um 'divisor de águas', devido às transformações que provoca nas diversas dimensões do processo de aprendizagem. A autora recomenda que se busquem alternativas pedagógicas que ajudem a potencializar transformações nas representações do senso comum dos alunos, responsáveis pelo medo, receio e ansiedade.

Essas investigações evidenciam a necessidade de aprofundarmos estudos junto às novas tendências pedagógicas, visando a romper com o modelo tradicional de educação que privilegia a transferência de conhecimento como um fim em si mesmo, a pouca flexibilidade dos currículos e a rigidez dos papéis do professor e do aluno, fatores que impedem a formação críticoreflexiva dos profissionais

Para Schön (2000), o currículo normativo das escolas e a separação entre a pesquisa e a prática não deixam espaço para a reflexão na ação, criando, assim, um dilema entre o rigor e a relevância para educadores, professores e estudantes. O autor propõe uma nova epistemologia da prática que lide mais facilmente com o conhecimento profissional, que deve partir da competência e do talento, especialmente o "pensar o que fazem, enquanto fazem".

O termo competência, em sua aplicação pedagógica, para Perrenoud (1999, p. 7), é a “capacidade de agir eficazmente em um determinado tipo de situação, apoiado em conhecimentos, mas sem limitar-se a eles". Para enfrentar ou solucionar determinadas situações com pertinência e eficácia, mobilizam-se vários recursos cognitivos, como saberes, capacidades, informações e outros. O autor afirma que as competências manifestadas durante as ações não são, em si mesmas, conhecimentos, mas sim, que utilizam, integram ou mobilizam tais conhecimentos.

A ausência da ação reflexiva do aluno, tão esperada para a aprendizagem crítica, negligencia, assim, o conceito de competência, que representa atualmente um desafio para o educador em enfermagem. Para Saeki et al. (1999), o 
professor tem por tarefa a formação da competência do profissional para trabalhar com o ser humano, desempenhando o papel de articular o conhecimento técnico ao desenvolvimento dos recursos internos do futuro profissional.

$\mathrm{Na}$ área de saúde mental, Barros e Egry (2001) descrevem um verdadeiro descompasso entre o ensino e a prática da enfermagem psiquiátrica e de saúde mental e destes com as políticas de saúde vigentes no país, que pregam a desinstitucionalização do doente mental. Desta forma, mais uma vez, o ensino superior está formando profissionais acríticos e pouco atuantes politicamente. Destacam que as políticas de saúde mental atuais priorizaram um novo e reformista enfoque da assistência ao doente mental, mas a prática de enfermagem, majoritariamente, ainda se dá no âmbito hospitalar. Nos casos em que encontramos enfermeiros atuando de forma inovadora nos serviços de atenção psicossocial ou ambulatorial, constatamos que este fazer diferenciado foi adquirido na prática, não na academia.

Para as autoras citadas, há um distanciamento evidente entre o saber reproduzido nas escolas e o praticado na assistência ao doente mental, resultando numa dicotomia entre o pensar acadêmico e o fazer assistencial. As escolas ensinam o relacionamento terapêutico, que é considerado pelos educadores como principal instrumento para o desenvolvimento da assistência de enfermagem psiquiátrica. Mas na prática, esses enfermeiros não experienciam o relacionamento terapêutico, pois não só estagiaram durante o processo de formação, como também atuarão profissionalmente em hospitais psiquiátricos que mantêm uma assistência medicalizada, ancorados numa cultura de segregação e exclusão social, nada favorável à aplicação prática do aprendido na escola.

Fraga (1993) faz referência a uma enfermagem psiquiátrica que se ocupa basicamente de atividades administrativas, incluindo uma supervisão de caráter controlador e disciplinador, distante da prestação de uma assistência digna ao paciente. A autora destaca que o enfermeiro costuma não optar por esta área quando se encontra diante de outra oportunidade de trabalho.

É o momento de o educador em enfermagem buscar novas estratégias de ensino que proporcionem situações de aprendizagem, mediante ações transformadoras. É necessário desenvolver o pensamento crítico e questionador, estimular a liderança, explorar as potencialidades de 'ser humano' em cada aluno, utilizando estratégias problematizadoras, deixando de lado o ensino tradicional. Chama-se a atenção para a oportuna formação de sujeitos partícipes do processo de transformação social e de transformação da enfermagem (Stacciarini e Esperidião, 1999).

Diante desta problemática, fomos buscar na pedagogia das competências amparo teórico para a mudança necessária para melhorar e atualizar nossos referenciais pedagógicos. Desenvolver competência nos alunos é prepará-los para a vida na sociedade moderna; é torná-los capazes de utilizar, integrar 
e mobilizar os conteúdos apreendidos, em situações práticas do cotidiano, na busca de solução de problemas. Para Perrenoud (2001, p. 1), “os alunos acumulam saberes, passam nos exames, mas não conseguem mobilizar o que aprenderam em situações reais, no trabalho e fora dele".

Consideramos fundamental que o educador em enfermagem parta em busca de estratégias de ensino que favoreçam o desenvolvimento da competência dos futuros profissionais. Perrenoud (2001) afirma ser necessário que o professor trabalhe por meio de resolução de problemas, propondo projetos e tarefas desafiadoras e complexas, incitando os alunos a mobilizarem seus conhecimentos. Ao professor cabe ser reflexivo, inovador e explorar uma pedagogia diferenciada.

A proposta deste estudo fundamenta-se, portanto, na necessidade de buscar novos pressupostos pedagógicos para a construção de competências no aluno de enfermagem, frente às dificuldades que parecem enfrentar para mobilizar o aprendido diante de situações práticas vividas durante o ensino da enfermagem psiquiátrica e de saúde mental. Propomos um diálogo entre a prática e o ensino da assistência em que docentes e enfermeiros trabalhadores possam indicar um caminho para a identificação e construção das competências necessárias para que o enfermeiro atue eficazmente em situações reais na saúde mental.

\section{Breve história do ensino de enfermagem}

O desenvolvimento da enfermagem psiquiátrica, enquanto campo específico do saber, tem sido influenciado pelo movimento da enfermagem, que avança de acordo com as mudanças que acontecem na sociedade e nas ciências médicas. A chamada 'enfermagem moderna' surgiu em meio a uma crise do pensamento científico, no momento em que a ciência passou a se acreditar neutra em face da história, independente das paixões do sujeito, quando se postulou isenta de ideologia (Miranda, 1994).

No Brasil, a primeira tentativa de sistematização do ensino da enfermagem ocorreu na área psiquiátrica, em que o hospício era o núcleo central da prática. A Escola Profissional de Enfermeiros no Hospício Nacional de Alienados foi criada por decreto do governo da República, de 1890, como resultado de um processo político que, ultrapassando os limites do hospício, pôs em confronto o poder do clero, do Estado e da classe médica (Barros e Egry, 2001).

Tavares afirma que, quando houve a institucionalização do ensino de enfermagem no Brasil, com a criação da Escola de Enfermagem Anna Nery em 1923, nos moldes 'nightingalianos', não houve interesse no ensino de enfermagem psiquiátrica: 


\begin{abstract}
“Nesse período, o ensino e a prática de enfermagem está voltada essencialmente para a atuação no campo de saúde pública, condizente com as necessidades do momento. O saber de enfermagem psiquiátrica não era contemplado nos currículos das escolas e sua prática continuava a ser desenvolvida independente do ensino formal da enfermagem nos moldes prevalentes da época" (Tavares, 1997, p. 22).
\end{abstract}

Fernandes (1982) relata em seu trabalho que, por volta de 1941, algumas escolas de enfermagem já se dedicavam ao ensino de enfermagem psiquiátrica, num contexto de franca expansão dos hospitais asilares, voltados para uma assistência de isolamento, disciplinadora e vigilante. O doente mental era concebido como um elemento nocivo, causador de danos à sociedade, e como tratamento, recebia eletrochoque, insulinoterapia e choque vespertino. A enfermagem atuava na vigilância, controle, auxílio aos tratamentos (eletrochoque e insulinoterapia), administração de medicação e contenção.

Somente em 1949, com a lei $\mathrm{n}^{\circ} 775$ e o decreto $\mathrm{n}^{\circ} 27.426$ (Brasil, 1949a, 1949 b), torna-se obrigatório o ensino de enfermagem psiquiátrica nos cursos de graduação em enfermagem, porém poucas eram as escolas de enfermagem que ofereciam estágios na área, e quando a prática ocorria, os campos eram precários (Fernandes, 1982; Tavares, 1997).

Tavares (1997) descreve a década de 1950 por meio de dois grandes marcos: o primeiro é o surgimento dos neurolépticos e antipsicóticos e o segundo, a utilização da psicanálise. As drogas determinaram a medicalização do doente e a psicanálise induziu à valorização dos aspectos psicológicos do comportamento humano, refletindo uma tímida relação dos aspectos clínicos da doença com os psicológicos. O autor relata, ainda, que a década de 1960 foi marcada pela deterioração do governo populista, e a assistência psiquiátrica, que era voltada para o indigente, foi ampliada para a classe trabalhadora e seus dependentes. Emerge a privatização dos leitos hospitalares (cresce o número de hospitais psiquiátricos privados financiados por recursos públicos), e a rede ambulatorial representa a porta de entrada para a hospitalização. O ensino de enfermagem psiquiátrica pouco muda, continua voltado para o plano biológico da doença.

Fernandes (1982) empreendeu uma análise dos programas de ensino de enfermagem psiquiátrica, compreendendo o período de 1930 a 1964, e pôde verificar a ênfase dada aos aspectos clínicos da doença mental, envolvendo terapêuticas biológicas e hospitalocêntricas. Nos anos que se seguem, há uma relativa mudança, com a inserção de princípios da psiquiatria preventiva, baseados na higiene mental, e movimentos da assistência de enfermagem, buscando noções sobre drogas e transtornos mentais. Os programas de ensino abordam terapia familiar e relacionamento terapêutico, atividades grupais, comunidades terapêuticas. 
O final da década de 1970 e o início da década seguinte são marcados por uma grande crise econômica mundial, fazendo com que as políticas sociais brasileiras fiquem relegadas ao segundo plano, mobilizando a opinião pública. Emergem os movimentos populares que reivindicam melhores condições de vida, como o da Reforma Sanitária, cujos princípios são consolidados na VIII Conferência Nacional de Saúde, em 1986, e que representou a base de sustentação para posterior efetivação do Sistema Único de Saúde (SUS). Também surgem os movimentos populares influenciados por movimentos internacionais, como o da Itália, que lutam por uma melhor assistência psiquiátrica.

O alto grau de insatisfação dos profissionais de saúde passa a ser expresso nas produções teóricas da época. A maioria dos manifestantes é composta por médicos, seguidos de uma mínima vanguarda de enfermeiros. Este quadro é justificado por Fernandes (1981) pela dificuldade do enfermeiro em lutar pela transformação do seu trabalho, por sua relação com o paciente, por não ter consciência de seu lugar na sociedade e da importância de seu papel, apontando para a necessidade de discussão e reflexão sobre a prática da enfermagem na área de saúde mental.

Em 1981, para Fernandes (1982), a enfermagem estava envolvida com reformulações sociais da época que lhe impunham necessidades de reforma, objetivando, na condição de prática social, o desempenho de suas funções políticas, ideológicas e econômicas. Como superestrutura político-ideológica, a enfermagem participa na normalização dos comportamentos considerados desviantes, na prevenção e atenuação das tensões sociais, visando ao controle e à manutenção da ordem. Como superestrutura econômica, a enfermagem participa da manutenção e recuperação da força de trabalho no âmbito das empresas prestadoras de serviços e da indústria farmacêutica. Mesmo assim, a autora revela em seu estudo que a enfermagem psiquiátrica passava por um quadro de escassez, mantendo em suas práticas atitudes repressivas e autoritárias, reproduzidas também nos ambulatórios.

Sena (1985, p. 393) afirma que o ensino de enfermagem psiquiátrica e de saúde mental nesse período "continua desligado do conjunto global no processo saúde-doença, cuja tendência dominante está centrada na assistência hospitalar, refletindo, assim, as tendências da medicina organicista de reforçar as ações curativas em detrimento das preventivas".

Nos anos que se seguem, a crítica ao velho modelo começa a se fazer presente, percebendo-se uma tendência de mudança, pelo menos no discurso, visando a um redimensionamento e ampliação da assistência de enfermagem, incluindo os três níveis de assistência à saúde e a preocupação com o usuário e contando com a participação da comunidade.

Podemos notar que o ensino de enfermagem psiquiátrica e de saúde mental na década de 1990 já estava fortemente influenciado pelas diretrizes 
da Reforma Psiquiátrica, surgindo contradições na forma de abordar saberes e práticas.

O trabalho de Braga e Rodrigues (1994) criticava os currículos de enfermagem, os quais se voltavam para capacitar o enfermeiro a atender as necessidades físico-biológicas do ser humano, destacando a tímida tentativa da disciplina de enfermagem psiquiátrica em fugir dessa visão organicista.

Outro trabalho que nos chamou a atenção foi o de Stefanelli et al. (1996), uma reflexão sobre a reestruturação da atenção nos moldes da Reforma Psiquiátrica preconizada pela Declaração de Caracas. Reflexão traduzida na expressão da necessidade de um novo paradigma, que fundamentasse novas práticas de enfermagem. Para tanto, as autoras obtiveram dados sobre o ensino de enfermagem, para posterior discussão e elaboração de um documento contendo diretrizes gerais que pudessem nortear o ensino de enfermagem em saúde mental. Este estudo, do tipo descritivo-exploratório, envolveu relatos de docentes de diversas escolas que revelaram a vivência de ensino em vários equipamentos de assistência psiquiátrica, como ambulatórios especializados de saúde mental, emergências psiquiátricas em pronto-socorro de hospital geral, enfermarias psiquiátricas em hospital geral, hospital-dia, casas de apoio, unidades básicas de saúde, pensões abrigadas, centros de convivência, unidade para moradores, Núcleo de Atenção Psicossocial (NAPS), Centro de Atenção Psicossocial (CAPS), oficinas de expressão e serviço de alfabetização.

Barros, em tese defendida em 1996, estudou o fato de o ensino de enfermagem psiquiátrica e de saúde mental não ter incorporado o discurso oficial da política de saúde mental. Na pesquisa, a autora procurou desvelar a prática deste ensino, expressa nos discursos de docentes da Escola de Enfermagem da Universidade de São Paulo, acerca da assistência em saúde mental. Como resultado, sumariamente, desvelou concepções do fenômeno saúde-doença enquanto processos distintos, entre o normal e o patológico, isto é, a saúde foi relatada como a ausência da doença, a adaptação e o equilíbrio; a doença, como própria do homem, manifesta pelo comportamento e pelos problemas de inter-relações (Barros e Egry, 2001).

No estudo mencionado, emergiram dois modelos de atenção, na concepção dos docentes sujeitos da pesquisa: o da psiquiatria, que cuida da doença, e o da saúde mental, fundamentado na psiquiatria preventiva. A pesquisa conclui que a assistência de enfermagem é voltada para um homem anistórico, buscando atender a doença manifestada pelo comportamento do paciente; o ensino preocupa-se com o processo ensino-aprendizagem do relacionamento terapêutico, que é inviável na prática, uma vez que o aluno estagia em hospitais psiquiátricos, lugar nada terapêutico. Afirma que o saber produzido no ensino não é reproduzido na assistência pela maioria dos enfermeiros, que acabam por atuar em locais nos quais o relacionamento terapêutico não é aplicável, reafirmando o descompasso existente entre o 
ensino e a prática de enfermagem em saúde mental e destes com as políticas de saúde da área.

Kantorski (1998) realizou sua tese fundamentada no trabalho de Barros (1996) e observou o ensino em quatro universidades públicas do Rio Grande do Sul considerando a Reforma Psiquiátrica, apontando as amarras na discussão e no comprometimento com o processo de mudança, traduzidas na rigidez dos currículos e programas das disciplinas da área, nos limites da formação dos docentes e na ocultação das diferenças internas. A adesão ao processo de reforma não partiu das instituições de ensino, mas de alguns sujeitos e atores sociais, por meio da aproximação das discussões e práticas diferenciadas, mobilizadas pelo inconformismo e pela resistência aos saberes e práticas psiquiátricas dominantes.

No contexto atual de transformação da assistência à saúde mental no Brasil, o ensino de enfermagem psiquiátrica vem direcionando esforços para a qualificação do profissional. Como exemplo, citaremos o trabalho de Barros et al. (1999), que relata experiência embasada nas diretrizes das recentes políticas de saúde mental, quando as docentes, empenhadas em estimular práticas de ensino, renovaram o ensino da assistência na área de saúde mental na Escola de Enfermagem da Universidade de São Paulo. Por meio do Programa de Integração Docente-Assistencial (PIDA), firmaram um convênio entre instituições públicas, formadoras e assistenciais, reestruturando os estágios da disciplina, que anteriormente eram realizados em hospitais psiquiátricos, e passando, gradativamente, a incluir outros serviços assistenciais, como o ensino sistematizado em CAPS. As autoras afirmam que esta

“(...) experiência redimensionou a relação dos alunos com usuários, técnicos e sua identidade profissional: pelas trocas efetivas, pela diversidade de intervenções, pelo aprendizado e interlocução com o serviço, pela inserção do docente na gestão do projeto, transformando o processo ensino-aprendizagem num encontro criativo e reflexivo" (Barros et al., 1999, p. 198).

Atitudes inovadoras no ensino de enfermagem psiquiátrica também são descritas por Villa e Cadete (2000), que iniciaram uma atividade de ensino e extensão com a participação do docente de enfermagem psiquiátrica em serviços de atenção à saúde mental não hospitalar, denominados Centros de Referência em Saúde Mental, na cidade de Belo Horizonte. Os alunos que vivenciaram este processo de mudança descreveram o aprendizado de forma bastante otimizada, como "uma nova concepção de atendimento em saúde mental", "a cidadania como direito do doente", "a reflexão entre a teoria e a prática", "assistência direta prestada pelo enfermeiro" e "sentimentos diversos, entre eles, a perda do medo". Segundo as autoras, os discentes declararam que, presenciando este modelo de assistência, foi possível apre- 
ender um atendimento à saúde mental norteado por uma nova concepção da loucura, fundamentado no resgate da cidadania; viram o enfermeiro atuando, efetivamente, na assistência, visualizando as vias de aplicação do conhecimento específico da área e contribuindo com o serviço, assim como para a desmistificação da loucura.

O processo de reorientação do modelo assistencial em saúde mental tem apresentado como um de seus temas a questão da formação de recursos humanos adequados às novas estruturas de atenção.

Um dos pontos fundamentais destacados pela III Conferência Nacional de Saúde Mental para a construção do novo modelo assistencial é a questão dos 'recursos humanos' (gestão com pessoas), considerando as dimensões que compõem as potencialidades das pessoas, isto é, os processos que podem enriquecer ou restringir estas potencialidades na elaboração, desenvolvimento e inserção nas políticas e projetos públicos. Todo esse processo envolve tanto a análise da situação atual dos trabalhadores no contexto SUS, como a compreensão dos problemas atuais e a elaboração de respostas, novas formas de cuidado do sofrimento, de relação dos profissionais com os usuários, familiares e comunidade e entre os próprios profissionais (MS, 2001).

Dessa maneira, a questão da formação do enfermeiro, particularmente na área de enfermagem psiquiátrica, deve ser contemplada de forma contextualizada, buscando-se analisá-la como um elemento partícipe de uma trama de relações políticas e econômicas. As práticas assistenciais organizam-se, em sua maioria, balizadas pelos discursos técnicos e acadêmicos, e muitas vezes são reproduzidas sem muita reflexão, crítica ou inovação.

Os professores, ao formularem seus planos de ensino e objetivos, acreditam que estão formando enfermeiros competentes para a prática assistencial em saúde mental, conforme os princípios da Reforma Psiquiátrica. Entendemos que esses professores poderão reconstruir esses planos de forma a construir competências, o que possibilitará ao aluno e ao enfermeiro uma prática transformadora.

Em face deste panorama, estamos desenvolvendo um estudo cuja finalidade é construir conhecimentos sobre competências necessárias para que o enfermeiro atue na área de psiquiatria e de saúde mental, buscando a transformação do ensino de enfermagem psiquiátrica e saúde mental, com base no referencial teórico da pedagogia das competências.

Para sua consecução, a pesquisa está sendo realizada a partir de dois temas, desenvolvidos por meio de subprojetos de pós-graduação e de iniciação científica, a saber: 1) a necessidade de construção de competências na formação do enfermeiro; e 2) interfaces da pedagogia das competências e contextos do processo ensino-aprendizagem. 


\section{Referencial teórico-metodológico}

Para melhor compreensão do fenômeno ensino-aprendizagem de enfermagem psiquiátrica e de saúde-mental, optamos por uma metodologia de abordagem qualitativa, que tem por objeto uma realidade que não pode ser quantificada, trabalhando com o universo dos significados, motivos, aspirações, crenças, valores e atitudes presentes nas relações e ações humanas (Minayo e Deslandes, 1998).

A investigação do objeto será orientada pela abordagem dialética marxista. Para compreender a dialética é necessário defini-la, e quem o faz de forma clara é Konder (1989, p. 8), afirmando que a dialética "é o modo de pensarmos as contradições da realidade, o modo de compreendermos a realidade como essencialmente contraditória e em permanente transformação".

Para Minayo, a dialética no marxismo

“(...) se transformou numa maneira dinâmica de interpretar o mundo, os fatos históricos e econômicos, assim como as próprias idéias, sob a égide de materialismo histórico (...) a dialética está presente como método de transformação do real, que por sua vez modifica a mente criando as idéias" (Minayo, 2002, p. 94).

Utilizaremos uma citação de Löwy para fundamentar nossa opção metodológica:

“(...) na medida em que se desenvolve um processo de conhecimento, ou um processo de transformação, ou um processo de prática social, inevitavelmente aparecem pontos de vista diferentes, aparecem divergências, contradições, concepções distintas, no seio de uma mesma classe social, ou daqueles que compartilham de uma mesma visão do mundo. Isto é inevitável e é também necessário, é parte de todo o processo efetivo de conhecimento e transformação de realidade" (Löwy, 1995, p. 35).

Portanto, a opção pela metodologia dialética deu-se pela coerência com a finalidade do estudo, que propõe a utilização da pedagogia das competências para desvendar quais competências são necessárias para que o enfermeiro atue na área de psiquiatria e de saúde mental, buscando-se a transformação do ensino de enfermagem nesta área.

O referencial teórico e as bases analíticas deste estudo serão conduzidos pelos pressupostos norteadores da pedagogia das competências, também conhecida por alguns autores como a pedagogia do 'aprender a aprender'. Para melhor compreensão deste referencial, faremos uma descrição sucinta. A construção das competências tem seus princípios fundamentados no construtivismo, que, para Becker, é: 


\begin{abstract}
“A idéia de que nada, a rigor está pronto, acabado, e de que, especificamente, o conhecimento não é dado, em nenhuma instância, como algo terminado. Ele se constrói pela interação do indivíduo com o meio físico e social, com o simbolismo humano, com o mundo das relações sociais; e se constitui por força de sua ação e não por qualquer dotação prévia, na bagagem hereditária ou no meio, de tal modo que podemos afirmar que antes da ação não há psiquismo nem consciência e, muito menos, pensamento" (Becker, 1994, p. 88-89).
\end{abstract}

No construtivismo, a questão epistemológica é a origem do conhecimento, que adere ao 'interacionismo', com o sujeito no papel central na produção do saber. O aprendiz é o sujeito de sua própria aprendizagem, e é capaz de conduzir sua compreensão do mundo. É como se dissessem aos educadores: “sejam o centro do processo de ensino: criem, junto com os alunos, os seus próprios caminhos; descubram alternativas pedagógicas em sala de aula" (Rosa, 2002, p. 49).

Assim, a pedagogia das competências norteará o estudo, como referencial teórico, entendendo-se competência como a capacidade do sujeito de mobilizar recursos cognitivos visando a abordar uma situação complexa.

A abordagem por competências é considerada por Perrenoud (1999) uma questão ao mesmo tempo de "continuidade" e de "ruptura". De continuidade porque faz parte do processo de evolução do mundo, das fronteiras, das tecnologias, dos estilos de vida que hoje requerem flexibilidade e criatividade dos seres humanos trabalhadores; portanto, as escolas têm como missão desenvolver a inteligência como capacidade multiforme de adaptação às diferenças e às mudanças. E de ruptura com aquela pedagogia que não prepara o indivíduo para enfrentar situações reais, e sim para prestar exames; um distanciamento das rotinas pedagógicas e didáticas, das compartimentações disciplinares, da segmentação do currículo, do peso da avaliação e da seleção, das imposições da organização escolar, que nada contribuem para construir competências.

As mudanças exigidas são muitas e seguem um movimento contemporâneo que vem ocorrendo em vários países. Comparando o novo paradigma com os princípios da educação brasileira, Mello (2003) descreveu que os princípios filosóficos eram baseados no direito de aprender; no novo paradigma, mantém-se esse direito, acrescido de uma estética de sensibilidade, política de igualdade e ética da identidade em todos os trabalhos. O conteúdo sempre foi tratado como um fim em si mesmo; no novo paradigma, é visto como um meio para desenvolver competência. O conhecimento, no velho paradigma esteve fragmentado, compartimentado, valorizando o ensino de regras, fatos, definições, acúmulo de informações desvinculadas da vida dos alunos, de caráter enciclopédico, privilegiando a memória e a padronização; em contrapartida, a nova forma de se conceber o conhecimento é integrando-o por meio do trabalho interdisciplinar e da contextualização, privilegiando a 
construção de conceitos e o entendimento. A teoria e a prática são aplicadas no cotidiano do aluno, com ênfase na produção e sistematização do sentido.

O velho paradigma tratou o currículo de forma fracionada, estática e linear. A mudança requer um currículo integrado, vivo e em rede, proporcionando a oportunidade de conhecer, fazer, relacionar, aplicar e transformar. A organização curricular, que antes se fazia por disciplinas, agora deve ser feita por áreas do conhecimento, eixo organizacional, tema gerador e conjunto de competências. A sala de aula foi até então vista como um espaço de transmissão e de recepção do conhecimento. Pelo novo paradigma, ela é considerada um espaço privilegiado de reflexão, de situações de aprendizagem vivas e enriquecedoras (Mello, 2003).

O papel do professor sofre várias transformações no novo paradigma, conduzindo aquele tradicional transmissor de conhecimento - determinador do conteúdo a ser trabalhado, sem levar em conta as necessidades que surgem em sala de aula - a se tornar um facilitador da aprendizagem do aluno e da construção dos sentidos, gerenciador da informação, reflexivo, aquele que avalia e ressignifica sua prática pedagógica, incentivador da estética da sensibilidade, e que zela pela política da igualdade e pela ética da identidade. O papel do aluno também é alvo de mudanças. Aquele aluno antes considerado passivo, receptáculo do conhecimento descontextualizado, que não sabe porque e para que estuda determinados conteúdos, passa a ser visto como ser altivo e participativo na construção do conhecimento (Mello, 2003).

Abordamos até agora o paradigma que orienta a reflexão dos autores que trabalham com o referencial teórico do construtivismo e com a abordagem pedagógica das competências. Mas qual será a relação deste paradigma com a dialética marxista?

Severino (1994) relata que a referência dialética para a educação se dá numa perspectiva histórico-social, sendo concebida como um processo individual e coletivo de constituição de uma nova consciência social e de reconstituição da sociedade por meio da rearticulação das relações políticas. O autor complementa: a educação é um evento social que se manifesta no tempo histórico. Quando encarada do ponto de vista de sua inserção social, a educação ganha o significado de uma prática social e histórica concreta, por tratar-se de um processo sociocultural que ocorre na história de uma sociedade, representando comportamentos sociais, costumes, instituições, atividades culturais, organizações burocrático-administrativas. Para Wachowicz (1995), é o método dialético que permite a abordagem da educação como um componente de transformação social. Para este autor, é a dialética que confere à educação o seu estatuto epistemológico adequado, que é o estatuto de ação. A dialética concebe a educação como uma ação, a pedagogia como uma teoria, e o saber como uma apropriação de determinada realidade, não apenas dos conteúdos elaborados sobre essa realidade. 
A interação entre a educação e o método dialético mais se evidencia nos referenciais adotados pelos próprios construtivistas, como Piaget, Vigotsky e Wallon, que abordam a realidade e o conhecimento do ponto de vista do processo histórico, identificando este posicionamento com a historicidade da dialética marxista (Matui, 1995).

Matui (1995) encontrou no trabalho de Lefebvre apoio teórico para descrever cinco leis da dialética que, segundo o autor, possibilitam a integração dos construtivistas, favorecendo a formulação de uma teoria passível de ser aplicada na educação ${ }^{4}$.

\section{A necessidade de construção de competências na formação do enfermeiro}

Com relação a este primeiro tema, são sujeitos da pesquisa todos os docentes que ministram o ensino de enfermagem psiquiátrica e de saúde mental em uma escola de enfermagem de universidade pública e os enfermeiros dos campos de prática utilizados no processo de ensino dos alunos cursando a disciplina.

Antecedendo as autorizações institucionais e pessoais para coleta de dados, este projeto foi encaminhado para apreciação e parecer da Comissão de Ética e Pesquisa e foi feita uma solicitação de autorização à chefia do departamento de ensino em enfermagem psiquiátrica e de saúde mental da instituição a ser pesquisada. Os sujeitos receberam o termo de consentimento informado, que esclarece os objetivos, finalidades e a construção da pesquisa, bem como fornece informações sobre o respeito ao sigilo e ao anonimato.

A coleta de dados ocorreu por meio de grupo focal. Várias referências da literatura convergem no sentido de que o grupo focal é uma técnica de obtenção de dados qualitativos, utilizada para mobilizar a discussão sobre um tema em particular, envolvendo sentimentos, emoções, opiniões e relações dos atores envolvidos no processo. Os dados são coletados a partir da discussão. Chiesa e Ciampone (1999) falam da riqueza da aplicação da técnica de grupos na pesquisa qualitativa, relevando tanto a coleta de dados quanto a possibilidade de formulação de alternativas para alguns problemas levantados e discutidos pelo grupo. As autoras buscam fundamentação técnica e teórica em Pichon-Rivière.

A coleta de dados foi realizada em três sessões de grupo focal, por meio da intervenção grupal, que buscou a construção do conhecimento em torno da discussão de competências do enfermeiro para atuar na área de psiquiatria e saúde mental, agora tendo como referencial a noção de competência construtivista.

Para a análise e interpretação dos dados coletados, utilizamos a técnica da análise de discurso. Segundo Silva (2002), a análise de discurso é reconhecida desde os anos finais da década de 1960, com os trabalhos de Pêcheux, destinando-se aos pesquisadores que buscam investigar a língua 
em uso, contemplando forma e função, considerando a língua na sua dualidade e a produção de sentido(s) do discurso como uma resultante de processos de interação social.

Os discursos coletados, durante as sessões de grupo focal, foram submetidos à técnica proposta por Fiorin e Savioli adaptada por Car, fundamentada na teoria da geração de sentido, em que se permite a depreensão das frases temáticas (Car e Bertolozzi, 1999).

\section{Interfaces da pedagogia das competências e contextos do processo ensino- aprendizagem}

Este segundo tema será desenvolvido a partir de dois estudos com abordagens semelhantes, buscando-se as interfaces. Um estudo será desenvolvido com professores de escolas de enfermagem de universidades públicas, e esta etapa corresponde a identificar junto aos docentes, em outras realidades institucionais, sociais e políticas, as possibilidades de implementação de diretrizes gerais para o ensino por competências.

As unidades de ensino serão contatadas e o projeto enviado aos comitês de ética em pesquisa, solicitando permissão para a investigação. Professoresdoutores daquelas unidades, que compõem o Diretório de Pesquisa coordenado por esta pesquisadora, serão treinados no desenvolvimento de grupo focal, assim como participarão de grupo de estudos sobre pedagogia das competências. Eles serão responsáveis pela coleta de dados e participarão da análise, que seguirá os passos descritos no tema anterior.

O outro estudo será desenvolvido com alunos de graduação que já tenham cursado a disciplina de enfermagem psiquiátrica nos cenários das três instituições de ensino envolvidas nos temas 1 e 2 deste projeto, e obedecerá aos mesmos procedimentos éticos para coleta e análise dos dados. Nesta etapa, pretende-se analisar as representações do usuário-aluno, considerado sujeito ativo da aprendizagem - que busca por si mesmo conhecimentos e experiências ao ser colocado em situações mobilizadoras de suas capacidades, manifestando a atividade intelectual, criadora e expressiva - e identificar as contradições dos discursos docentes/discentes.

\section{Resultados preliminares}

O desenvolvimento da pesquisa, para consecução do primeiro tema, tem desvelado que seu objeto é bastante complexo. Assim, é fundamental explicitar nossas reflexões, constituídas durante o caminho da pesquisa e na aproximação com o material empírico já coletado. 
Presenciamos um predomínio dos modelos pedagógicos tradicionais e tecnicistas nas práticas de ensino de enfermagem, que na atualidade são considerados burocráticos e pouco significativos para o aluno.

Para romper com esta situação, é necessário que o educador em enfermagem tenha clareza quanto ao momento histórico e social em que se encontra e quanto aos paradigmas contemporâneos que devem ajustar sua prática educativa, transformando a dimensão técnica do ensinar. É fundamental rever e questionar o ensino de enfermagem psiquiátrica e de saúde mental, refletindo sobre a práxis; buscar novas estratégias de ensino que proporcionem situação de aprendizagem, mediante ações transformadoras e que favoreçam o desenvolvimento da competência dos futuros profissionais.

Os enfermeiros atribuem sentidos diversos ao conceito de competência e revelam uma insatisfação com o modelo pedagógico aplicado em sua formação geral, que é muito voltado para os moldes tecnicista e tradicional; concordam que ainda se utilizam desses modelos, mas conseguem fazer a crítica, e se encontram em processo de mobilização em busca de outros modelos. A superação está em movimento.

\section{Notas}

${ }^{1}$ Professora do Departamento de Enfermagem Psiquiátrica da Escola de Enfermagem da Universidade de São Paulo (USP). Doutora em Enfermagem pela USP. <sobarros@usp.br>

${ }^{2}$ Professora do Departamento de Enfermagem da Universidade do Estado de Mato Grosso (Unemat). Doutora em Enfermagem pela Universidade de São Paulo (USP). $<$ roselma@acif.com.br>

${ }^{3}$ Este artigo parte do projeto de pesquisa intitulado "Processo ensino-aprendizagem em saúde mental frente às mudanças de paradigma nas áreas de saúde e educação", financiado pelo CNPq e vinculado à Escola de Enfermagem da Universidade de São Paulo. A pesquisa encontra-se em andamento.

${ }^{4}$ No texto original do projeto de pesquisa, descrevemos sucintamente estas leis, consideradas por Lefebvre (1975, p. 237) "supremamente objetivas, sendo ao mesmo tempo leis do real e leis do pensamento, isto é, leis de todo o movimento, tanto do real quanto do pensamento". 


\section{Referências}

BARROS, Sônia. 1996. O louco, a loucura e a alienação institucional: o ensino de enfermagem. Tese de Doutorado, São Paulo: Escola de Enfermagem, Universidade de São Paulo.

; EGRY, Emiko Yoshikawa. 2001. O

louco, a loucura e a alienação institucional: o ensino de enfermagem sub judice. São Paulo: Cabral.

BARROS, Sônia et al. 1999. Tentativas inovadoras na prática de ensino e assistência na área de saúde mental. Revista da Escola de Enfermagem da USP, v. 33, n. 2, p. 192-199.

BECKER, Fernando. 1994. O que é construtivismo? São Paulo: FDE, (Idéias; n. 20).

BRAGA, Violante A. B.; RODRIGUES, Antonia R. F. 1994. A disciplina enfermagem psiquiátrica: expectativas da aluna. Semina: Ciências Biológicas/Saúde, v. 15, n. 2, p. 181-187.

BRASIL. 1949a. Lei ${ }^{\circ} .775$, de 6 de agosto de 1949. Dispõe sobre o ensino de enfermagem no país e da outras providências.

1949b. Decreto $n^{\circ} .27 .426$, de 14 de novembro de 1949. Aprova o regulamento básico para os cursos de enfermagem e de auxiliar de enfermagem.

CAR, Márcia Regina; BERTOLOZZI, Maria Rita. 1999. O procedimento da análise de discurso. In: ABEN (Associação Brasileira de Enfermagem). A classificação internacional das práticas de enfermagem em saúde coletiva (Cipesc). Brasília: Aben, p. 348-355. (Série Didática; Enfermagem no SUS).

CHIESA, Ana Maria; CIAMPONE, Maria. Helena T. 1999. Princípios gerais para a abordagem de variáveis qualitativas e o emprego da metodologia de grupos focais. In: ABEN (Associação Brasileira de Enfermagem). A classificação internacional das práticas de enfermagem em saúde coletiva (Cipesc). Brasília: Aben, p. 306-324. (Série Didática; Enfermagem no SUS).

FERNANDES, Josicelia D. 1981 A enfermagem no contexto da saúde mental. Revista Baiana de Enfermagem, v. 1, p. 7-23. Número especial.
1982. O ensino de enfermagem e de enfermagem psiquiátrica no Brasil. Dissertação de Mestrado, Salvador, BA: Escola de Enfermagem, Universidade Federal da Bahia.

FRAGA, Maria Nazaré de O. 1993. A prática de enfermagem psiquiátrica: subordinação e resistência. São Paulo: Cortez.

GENTILE, Paola E.; BENCINI, Roberta. 2002. Construindo competências. Relato de entrevista com Philippe Perrenoud na Universidade de Genebra, Suiça. Disponível em: <novaescola.abril.uol. com.br/ed/135_set00/html/fala_mestre. htm >. Acesso em: 28 maio 2001.

KANTORSKI, Luciane P. 1998. O ensino de enfermagem psiquiátrica e saúde mental e a reforma psiquiátrica no Rio Grande do Sul. Tese de doutorado, Ribeirão Preto, SP: Escola de Enfermagem de Ribeirão Preto, Universidade de São Paulo.

KONDER, Leandro. 1989. O que é dialética. $20^{a}$ ed. São Paulo: Brasiliense.

LEFEBVRE, Henri. 1975. Lógica formal, lógica dialética. Tradução de Carlos Nelson Coutinho. Rio de Janeiro: Civilização Brasileira.

LÖWY, Michael. 1995. Ideologias e ciência social: elementos para uma análise marxista. $10^{a}$ ed. São Paulo: Cortez.

MATUI, Jiron. 1995. Construtivismo: teoria construtivista sócio-histórica aplicada ao ensino. São Paulo: Moderna.

MELLO, Guiomar N. de. 2003. As necessidades básicas de aprendizagem dos professores: um enfoque útil à formulação de políticas. In: III Seminário Internacional de Educação. Porto Alegre, RS. Livro-resumo. São Paulo. p. 29-35.

MINAYO, Maria Cecília de S. 2002. Hermenêutica-dialética como caminho social. In: ; DESLANDES, Suely F. (orgs.). Caminhos do pensamento: epistemologia e método. Rio de Janeiro: Ed. Fiocruz, p. 83-107.

; DESLANDES, Suely F. 1998. Ciência, técnica e arte: o desafio da pesquisa. In: MINAYO, Maria Cecília S. et al. Pesqui- 
sa social: teoria, método e criatividade. 9a ed. Petrópolis: Vozes, p. 9-29.

MIRANDA, Cristina L. 1994. O parentesco imaginário: história e representação social da loucura nas relações de espaço asilar. São Paulo: Cortez.

MS (Ministério da Saúde). Secretaria de Assistência à Saúde. Conselho Nacional de Saúde. 2001. Relatório final da III Conferência Nacional de Saúde Mental: cuidar sim, excluir não. $1^{\text {a }}$ ed. Brasília.

PERRENOUD, Philippe. 1999. Construindo as competências desde a escola. Porto Alegre: Artmed.

2000. Pedagogia diferenciada. Porto Alegre: Artmed.

ROSA, Sany S. 2002. Construtivismo e mudança. $8^{a}$ ed. São Paulo: Cortez.

SAEKI, Toyoko et al. 1999. Reflexões sobre o ensino de dinâmica de grupo para alunos de graduação em enfermagem. Revista da Escola de Enfermagem da USP, v. 33, n. 4, p. 342-347.

SCHÖN, Donald A. 2000. Educando o profissional reflexivo: um novo design para o ensino e a aprendizagem. Porto Alegre: Artmed.

SENA, Tereza de Jesus. 1985. O ensino de enfermagem psiquiátrica e sua influência sobre a prática profissional. In: XXXVII Congresso Brasileiro de Enfermagem, Recife, PE. Anais. Recife:
Associação Brasileira de Enfermagem (Aben). p. 390-394.

SEVERINO, Antônio. 1994. Filosofia da educação: construindo a cidadania. São Paulo: FTB.

STACCIARINI, Jeanne M. R; ESPERIDIÃO, Elizabeth. 1999. Repensando estratégias de ensino no processo de aprendizagem. Revista Latino Americana de Enfermagem, v. 7, n. 5, p. 59- 66.

STEFANELLI, Maguida C. et al. 1996. Integração dos conceitos saúde mental nos cursos de graduação em enfermagem. Revista Paulista de Enfermagem, v. 15, n. 1-3, p. 51-65.

TAVARES, José L. 1997. Enfermagem psiquiátrica no Brasil: reflexões sobre o ensino e a prática. Revista Baiana de Enfermagem, v. 10, n. 1-2, p. 19-29.

VAIE, Sylvia. 2002. A vivência do estudante de enfermagem cursando a disciplina enfermagem psiquiátrica: 'divisor de águas'. Dissertação de Mestrado, São Paulo: Escola de Enfermagem, Universidade de São Paulo.

VILLA, Eliana A.; CADETE, Matilde Meire M. 2000. Portas abertas: novas possibilidades no ensino da enfermagem psiquiátrica. Revista Latino-Americana de Enfermagem, v. 8, n. 6, p. 13-19.

WACHOWICZ, Lilian A. 1995. O método dialético na didática. $3^{\mathrm{a}}$ ed. Campinas: Papirus.

Recebido em 05/12/2005

Aprovado em 10/04/2006 
